\title{
Fatty acids and CHD
}

\author{
Jayne V. Woodside ${ }^{1 *}$ and Daan Kromhout ${ }^{2,3}$ \\ ${ }^{1}$ Nutrition and Metabolism Group, Centre for Clinical and Population Science, Queen's University, Belfast, Mulhouse \\ Building, Grosvenor Road, Belfast BT12 6BJ, Northern Ireland \\ ${ }^{2}$ Director Nutrition, Medicines and Consumer Safety Division - RIVM, PO Box 1, 3720 BA Bilthoven, The Netherlands \\ ${ }^{3}$ Division of Human Nutrition, Wageningen University, PO Box 8129, 6700 EV Wageningen, The Netherlands
}

\begin{abstract}
During the last century much evidence has accumulated to suggest that from a public health perspective the type of fat is more important than the amount of fat. Saturated and trans-fatty acids increase and both $n-6$ and $n$-3 PUFA decrease the risk of CHD. Most of the knowledge about the effects of dietary fatty acids on CHD risk is based on observational studies and controlled dietary experiments with intermediate end points (e.g. blood lipoprotein fractions). Information from high-quality randomised controlled trials on fatty acids and CHD is lacking. The Netherlands Institute for Public Health has calculated the potential health gain that can be achieved if the fatty acid composition of the current Dutch diet is replaced by the recommended fatty acid composition. The recommendations of The Netherlands Health Council are: saturated fatty acids $<10 \%$ energy intake; trans-fatty acids $<1 \%$ energy intake; fish consumption (an indicator of $n$-3 PUFA) once or twice weekly. Implementation of this recommendation could reduce the incidence of CHD in The Netherlands by about 25000 /year and the number of CHD-related deaths by about 6000/year and increase life expectancy from age 40 years onwards by 0.5 year. These projections indicate the public health potential of interventions that modify the fatty acid composition of the diet.
\end{abstract}

\section{CHD: Fat type: Health benefits: Evidence}

CHD is a major cause of morbidity and mortality in Europe (De Backer et al. 2003). There are well-established risk factors for CHD, including smoking, high blood pressure, raised total cholesterol and HDL-cholesterol, and type 2 diabetes (De Backer et al. 2003). In terms of nutrition a diet high in saturated fat has been shown to be associated with the incidence of CHD (Mann, 2002). The observation that Greenland Eskimos (Inuit) have a low incidence of CHD despite a high saturated fat intake (Dyerberg \& Bang, 1979) has led to much scientific and public interest in the role of the various fatty acids in the prevention and treatment of disease, and particularly CHD. In the present review the biochemistry and dietary intake of the various fatty acids will be discussed, and the evidence linking them and their food sources with CHD will be reviewed.

\section{Biochemistry of fatty acids}

Fatty acids are hydrocarbon chains with terminal methyl and carboxyl groups. A vast number of fatty acids occur in nature and they differ in chain length, number of double bonds and type of double bonds. However, there are probably less than twenty that are quantitatively important in the human diet. Of these twenty, two (palmitic acid and oleic acid) often account for $\geq 65 \%$ of the total fatty acid intake. Table 1 describes the most commonly-occurring fatty acids, grouped as saturated fatty acids (SFA), MUFA and PUFA, depending on the presence and number of double bonds.

Of the total dietary intake of fatty acids $>95 \%$ is in the form of triacylglycerol. Most natural food sources contain a wide variety of SFA and unsaturated fatty acids, and thus a large number of triacylglycerol molecules of different fatty acid composition. Dietary fatty acids fulfil three major roles: an energy source; structural components of membranes; precursors to other molecules. Dietary fat represents a convenient energy-rich food source, but the role of fatty acids as energy providers can be adequately fulfilled by carbohydrate, while the major fatty acids found in membranes can be manufactured in the body. However, linoleic acid and $\alpha$-linolenic acid cannot be made by

\footnotetext{
Abbreviations: MI, myocardial infarction; SFA, saturated fatty acids.

*Corresponding author: Dr Jayne Woodside, fax +442890235900, email j.woodside@qub.ac.uk
} 
Table 1. Common dietary fatty acids

\begin{tabular}{|c|c|c|}
\hline Fatty acid & Formula & Common food sources \\
\hline \multicolumn{3}{|l|}{ Saturated } \\
\hline Lauric & $12: 0$ & Coconut oil, palm kernel oil \\
\hline Myristic & 14:0 & $\begin{array}{l}\text { Coconut oil, palm kernel oil, } \\
\text { dairy products }\end{array}$ \\
\hline Palmitic & $16: 0$ & Dairy products, meat, palm oil \\
\hline Stearic & $18: 0$ & Cocoa butter, meat \\
\hline \multicolumn{3}{|l|}{ MUFA } \\
\hline Oleic & Cis-18:1 & Olive oil, rapeseed oil, meat \\
\hline Elaidic & Trans-18: 1 & Hydrogenated fats \\
\hline \multicolumn{3}{|l|}{ PUFA } \\
\hline Linoleic & $18: 2 n-6$ & $\begin{array}{l}\text { Sunflower, maize and safflower } \\
\text { oils }\end{array}$ \\
\hline$\alpha$-Linolenic & $18: 3 n-3$ & $\begin{array}{l}\text { Linseed oil, soyabean oil, } \\
\text { vegetables }\end{array}$ \\
\hline EPA & $20: 5 n-3$ & Fish, marine mammals \\
\hline DHA & $22: 6 n-3$ & Fish, marine mammals \\
\hline
\end{tabular}

animals and are thus described as essential fatty acids, apparently as a result of their requirements in membranes and as eicosanoid (such as thromboxanes, prostaglandins, prostacyclins and leukotrienes) precursors.

\section{Biological effects of the various classes of fatty acid}

\section{Effect of fatty acids and dietary cholesterol on serum cholesterol: meta-analyses and the Keys equation}

It is 40 years since Keys \& Parlin (1966) and, working independently, Hegsted et al. (1965) developed predictive equations to quantify the effects of fatty acids and dietary cholesterol on plasma cholesterol concentrations. The numerous controlled feeding studies of the effects of different fatty acids on cholesterol levels have been summarised in several meta-analyses (Hegsted et al. 1965; Keys \& Parlin, 1966; Mensink \& Katan, 1992; Hegsted et al. 1993; Yu et al. 1995). These analyses confirm early reports by Keys \& Parlin (1966) and Hegsted et al. (1965) that total cholesterol and LDL-cholesterol are increased by SFA and decreased by PUFA. A recent meta-analysis shows that different fatty acids also have a different effect on HDL-cholesterol (Mensink et al. 2003).

Saturated fatty acids. SFA increase plasma total cholesterol and LDL-cholesterol levels by decreasing LDL receptor-mediated catabolism (Spady et al. 1983; Nicolosi et al. 1990). However, not all SFA affect total cholesterol and LDL-cholesterol concentrations in the same manner. Stearic acid has little effect on plasma cholesterol concentrations (Hegsted et al. 1965; Grande et al. 1970), which has been proposed to be a result of the rapid conversion of stearic acid in the body to oleic acid (Grundy \& Denke, 1990). There is also evidence that the chain length of the SFA is related to their effects on HDL-cholesterol, in that the longer the chain length the smaller the effect on HDL-cholesterol. Lauric acid increases HDL-cholesterol and palmitic and stearic acid do not affect HDL-cholesterol (Mensink et al. 2003). SFA can also compromise platelet function (Turpeinen et al. 1998).
MUFA. The biological effects of MUFA depend on whether the MUFA are in the cis or trans configuration. Cis-MUFA are relatively neutral in relation to their effects on LDL and HDL (Mensink, 2005), but transMUFA have been shown to increase LDL and decrease HDL (Lichtenstein et al. 1993, 1999; Mensink et al. 2003; Mensink, 2005). Trans-MUFA also increase plasma levels of lipoprotein (a) (Nestel et al. 1992; Sundram et al. 1997) and triacylglycerols (Katan et al. 1995), and may reduce endothelial function by impairing flow-mediated dilation (de Roos et al. 2001).

PUFA. Dietary PUFA are sub-classified as $n-6$ or $n-3$, depending on the location of the $\mathrm{C}$ atom involved in the first double bond from the methyl end of the chain.

The major $n-6$ fatty acid is linoleic acid. Numerous metabolic studies have shown that linoleic acid has a lowering effect on total cholesterol and LDL-cholesterol (Grundy et al. 1982; Sacks, 1994; Mensink et al. 2003), while other beneficial effects include improvement in platelet function (Mutanen \& Freese, 1996), improved insulin sensitivity (Lovejoy \& DiGirolamo, 1992; Lovejoy, 1999) and anti-arrhythmic effects (Abeywardena et al. 1991).

$n$-3 PUFA have wide-ranging biological effects. They have been shown to lower triacylglycerols (Kris-Etherton et al. 2002), with a review of human studies reporting that approximately $4 \mathrm{~g} n$-3 PUFA from fish oil/d decreases serum triacylglycerols by $25-30 \%$, with an accompanying increase in LDL-cholesterol and HDL-cholesterol of $1-3 \%$. The lowering effect increases as the supplement dose increases (Harris et al. 1988). $n$-3 PUFA also reduce VLDL and IDL (Lu et al. 1999; Tholstrup et al. 2004). They have been associated with a decreased risk of arrhythmias, with studies in cell cultures and animal models, observational studies and human intervention trials all suggesting that $n-3$ PUFA may protect against fatal arrhythmia (Charnock, 1994; Nair et al. 1997). The proposed mechanism appears to involve a stabilising effect on the myocardium itself (Nair et al. 1997; Kris-Etherton et al. 2002; Lee \& Lip, 2003). n-3 PUFA seem to have a small dose-dependent hypotensive effect (Howe, 1997), and the extent of the reduction in blood pressure appears to be dependent on the initial extent of hypertension (Howe, 1997). A meta-analysis has indicated a marked reduction in blood pressure of $3 \cdot 4 / 2 \cdot 0 \mathrm{mmHg}$ in hypertensive subjects consuming 5.6 g n-3 PUFA/d (Morris et al. 1993). n-3 PUFA have been shown to reduce platelet aggregation (Agren et al. 1997; Mori et al. 1997), thereby reducing haemostasis. $n$-3 PUFA appear to have an anti-atherogenic action, in that they can inhibit new plaque development (Eritsland et al. 1996); for example, EPA and DHA may alter expression of adhesion molecules. Abe et al. (1998) have reported a $9 \%$ reduction in intercellular adhesion molecule-1 and a $16 \%$ reduction in E-selectin but no change in vascular cell adhesion molecule-1 in hypertriacylglycerolaemic subjects receiving $n$-3 PUFA supplementation over 7-12 months, while $\alpha$-linolenic acid has been proposed to have similar effects (Rallidis et al. 2004). However, other studies have failed to confirm these results (Seljeflot et al. 1998; Johansen et al. 1999). It has been shown in several studies that $n$-3 PUFA improve 
endothelial function (for review, see Chin \& Dart, 1995), and they also favourably influence arterial compliance (McVeigh et al. 1994). A recent study has shown that $n-3$ PUFA from dietary fish oil supplements are readily incorporated into advanced atherosclerotic plaques and that this process is associated with structural changes consistent with increased plaque stability (Thies et al. 2003). n-3 PUFA may also be associated with a reduced inflammatory response (de Caterina \& Libby, 1996; Endres \& von Schackey, 1996; de Caterina et al. 2000; Simopoulos, 2002; Trebble et al. 2003; Zhao et al. 2004).

\section{Dietary measures to reduce LDL-cholesterol}

There is no evidence that moderate changes in total fat intake without changes in fatty acid composition have any beneficial effect on LDL-cholesterol. However, a number of dietary measures with the potential to lower LDLcholesterol have been tested in controlled intervention studies. A reduction in saturated fat, trans-fat and dietary cholesterol intake and an increase in soluble dietary fibre and plant sterol or stanol intake have all been shown to independently decrease serum LDL (Krauss et al. 2000; Kreisberg \& Oberman, 2003), whilst a combined dietary approach, which is low in saturated fat and high in plant sterols, soyabean protein, viscous fibres and almonds (Amygdalus communis L.), has been shown to produce a lowering effect on LDL-cholesterol similar to that of a statin (Jenkins et al. 2003).

\section{Epidemiological evidence linking consumption of fatty acids with CHD}

Serum cholesterol and CHD

Serum total cholesterol concentration is positively related to CHD mortality and is accepted as being a classical risk factor for CHD. The linear relationship between cholesterol and CHD mortality has been confirmed across cultures (Verschuren et al. 1995). Thus, the fact that the various fatty acids have different effects on total cholesterol leads to an expectation that they will also have different effects on CHD mortality.

\section{Saturated fatty acids and CHD}

Geographic and migration studies show strong positive correlations between saturated fat intake and rates of CHD (Kato et al. 1973; Keys, 1980; Kromhout et al. 1995b). Although these data provide evidence for the importance of environmental factors in the cause of CHD, they are seriously confounded by other dietary, lifestyle and social factors. Prospective studies have also examined the link between saturated fat and CHD (Garcia-Palmieri et al. 1980; Gordon et al. 1981; Shekelle et al. 1981; Kromhout et al. 1984; McGee et al. 1984; Kushi et al. 1985; Ascherio et al. 1996; Hu et al. 1997; Pietinen et al. 1997), but only two studies have found a positive association between saturated fat intake and risk of CHD (McGee et al. 1984; Kushi et al. 1985). The early studies of fat and CHD were limited by small study size, inadequate dietary assessment and inadequate adjustment for total energy intake, other types of fat or for trans-isomer fat intake (Hu et al. 2001; Hu \& Willett, 2002).

To date, the largest study of fat intake, which also had four repeated dietary assessments, was carried out in the Nurses' Health Study cohort of 80082 women followed up over 14 years (Hu et al. 1997). This study has found a weak positive association between saturated fat intake and risk of CHD.

\section{MUFA and CHD}

Ecological studies have suggested an inverse association between MUFA intake and total mortality, as well as CHD-related death (Jacobs et al. 1992). In particular, the mortality rate from CHD is very low in the traditional Mediterranean populations that use olive oil as the primary source of fat (Grundy et al. 1982). Prospective cohort studies examining MUFA intake and CHD risk are sparse. Two studies (Posner et al. 1991; Esrey et al. 1996) have found an increased risk of CHD with a higher intake of MUFA in younger, but not older, participants. However, neither study adjusted for intake of other fat types. A more recent study (Pietinen et al. 1997) that did adjust for other fat intake has found an inverse association. The Nurses' Health Study (Hu et al. 1997) has found an inverse association between MUFA intake and CHD risk.

\section{Trans-fatty acids and CHD}

The Nurses' Healthy Study (Hu et al. 1997) has found a strong positive association between trans-fatty acid intake and CHD risk. In addition to the Nurses' Health Study (Hu et al. 1997), three other large prospective studies (Ascherio et al. 1996; Pietinen et al. 1997; Oomen et al. 2001) have found elevated risk from CHD to be associated with higher trans-fatty acid intake. The results of these four prospective studies have been combined, and the pooled relative risk of CHD associated with a difference of $2 \%$ energy in trans-fatty acid intake assessed at baseline is $1 \cdot 25$ (95\% CI 1.11, 1.40; Oomen et al. 2001).

\section{n-6 PUFA and CHD}

In prospective cohort studies among men a strong inverse association between CHD and PUFA intake has been shown in the Western Electric Study (Shekelle et al. 1981), and borderline inverse associations have been reported in the Ireland-Boston Heart Study (Kushi et al. 1985) and the control group of the Multiple Risk Factor Intervention Trial (Dolecek, 1992). An inverse association between PUFA intake and CHD has also been shown in the Nurses' Health Study (Hu et al. 1997).

\section{n-3 PUFA and CHD}

Marine-derived n-3 PUFA. Epidemiological studies have consistently shown that consumption of at least one portion of fish weekly may decrease the risk of fatal CHD by approximately $40 \%$ compared with consumption of no fish (Kromhout et al. 1985, 1995a; Shekelle et al. 1985; 
Dolecek \& Granditis, 1991). More recently, in a 30-year follow-up of the Chicago Western Electric Study men who consumed $\geq 35 \mathrm{~g}$ fish daily compared with those who consumed none had a relative risk of death from CHD of 0.62 (Daviglus et al. 1997). The association between marine-derived $n-3$ PUFA and CHD has also been shown for fatal CHD, but not for non-fatal myocardial infarction (MI), in a prospective study in the elderly (Lemaitre et al. 2003). A meta-analysis of prospective studies has confirmed the association, but only in high-risk groups (Marckmann \& Gronbaek, 1999), while a more recent meta-analysis has also found a protective effect of fish consumption on CHD (relative risk 0.86 (95\% CI 0.81 , 0.92); $P<0.005$; Whelton et al. 2004). A separate metaanalysis has confirmed the association, finding each $20 \mathrm{~g} / \mathrm{d}$ increase in fish intake to be related to a $7 \%$ lower risk of CHD mortality $(P=0 \cdot 03$; He et al. 2004). The inverse association between fish consumption and mortality from CHD has been shown to be consistent across countries in an ecological study of thirty-six countries (Zhang et al. 1999).

Fewer studies have examined the effect of tissue $n-3$ PUFA levels rather than dietary intake on CHD risk. In the European Multicentre Case-Control Study on Antioxidants, Myocardial Infarction and Breast Cancer (Guallar et al. 1999), a large international case-control study, no association between adipose tissue DHA and MI risk was demonstrated. However, a Finnish study (Erkkila et al. 2003), carried out in the context of the EUROASPIRE study, has examined the fatty acid composition of serum cholesteryl esters in relation to secondary prevention of CHD. The relative risk of death, adjusted for CVD risk factors, for subjects in the highest tertile of fatty acids compared with those in the lowest tertile was found to be 0.33 for $\alpha$-linolenic acid, 0.33 for EPA and 0.31 for DHA $(P=0.063,0.056$ and 0.026 respectively for trend).

Some notable studies have not reported an association between fish consumption and CHD risk. In the Health Professionals Follow-up Study (Ascherio et al. 1995) no association between fish intake (and $n$ - 3 PUFA intake) and risk of CHD was found. Similarly, the Physicians Health Study (Albert et al. 1998) has also failed to show an association between fish consumption or $n$-3 PUFA intake and risk of MI, non-sudden cardiac death or total CVD mortality, although a reduced risk of sudden cardiac death and total mortality was reported. The Seven Countries data (Kromhout et al. 1996) has also shown a lack of association between fish consumption and both CHD incidence and mortality. In fact, The Alpha-Tocopherol, BetaCarotene Cancer Prevention Study (Pietinen et al. 1997) has found that the estimated $n-3$ PUFA intake from fish is associated with a trend towards increased risk of death from CHD (after adjustment for trans-fatty acids, SFA and cis-MUFA).

The authors of the American Heart Association scientific statement on fish consumption, fish oil, $n-3$ fatty acids and CVD (Kris-Etherton et al. 2002) have summarised the possible reasons for the conflicting data from the epidemiological studies. There have been suggestions that the conflicting data reflect differences in the definition of sudden death and the residual confounding of reference groups that have a less-healthy lifestyle (Kromhout, 1998), variability in end points studied, study design or dietary assessment of fish intake, different study populations (Sheard, 1998) and the possible confounding effect of an increase in haemorrhagic stroke. Albert et al. (1998) have attempted to explain the lack of association in their study as being because only a small proportion of their population reported little or no fish consumption, whereas the studies reporting an inverse association between fish consumption and mortality from $\mathrm{CHD}$ have had relatively large proportions of the study population that do not eat fish. The European Multicentre Case-Control Study on Antioxidants, Myocardial Infarction and Breast Cancer (Marckmann \& Gronbaek, 1999) only examined MI survivors, and it is possible that those who did not survive ate less fish. Another explanation, based on a summary of eleven prospective studies, is that fish is protective in populations at high risk of CHD but not in populations at low risk. Another consideration is the type of fish consumed and how it is prepared; Oomen et al. (2000) have reported a lower CHD mortality (relative risk 0.66) only in those eating fatty fish and not in those eating lean fish. Another emerging explanation relates to levels of methylmercury in fish, with several, although not all, studies showing an association between methylmercury exposure and CHD risk (Ahlqwist et al. 1999; Salonen et al. 2000). Thus, methylmercury in fish may mask the beneficial effects of $n$-3 PUFA on CHD risk. This possibility has been confirmed in an analysis of the European Multicentre Case-Control Study on Antioxidants, Myocardial Infarction and Breast Cancer (Guallar et al. 2002).

Plant-derived $\mathrm{n}-3$ PUFA. $\alpha$-Linolenic acid, in contrast to EPA and DHA, is found in plant foods and not marine sources. Evidence from epidemiological studies of $\alpha$-linolenic acid and CVD indicates that $\alpha$-linolenic acid is associated with a lower risk of both MI and fatal CHD in both women and men (Kris-Etherton et al. 2002). A recent meta-analysis of five prospective studies of $\alpha$-linolenic acid and mortality from CHD (Brouwer et al. 2004) has concluded that high $\alpha$-linolenic acid intake is associated with a reduced risk of fatal CHD (relative risk 0.79 $(95 \%$ CI $0.60,1.04)$ ). In addition, in a recent observational study (Djousse et al. 2003) higher consumption of $\alpha$-linolenic acid has been shown to be associated with a lower prevalence of carotid plaques and with lower segment-specific carotid intima-media thickness. In the same cohort dietary $\alpha$-linolenic acid has been associated with a lower prevalence of calcified atherosclerotic plaque in the coronary arteries (Djousse et al. 2005).

\section{Nut consumption and CHD risk}

Dietary recommendations to reduce the risk of CHD have traditionally advised the avoidance of nuts because of their high fat content ( $\leq 80 \%$ energy from fat). However, epidemiological evidence (Hu \& Stampfer, 1999) supports a protective effect of nut consumption and CHD. Intervention studies have confirmed the cholesterol-lowering effects of walnut (Juglans regia)-rich (Sabate, 1993), almond-rich (Spiller et al. 1992; Abbey et al. 1994) and peanut (Arachis hypogea)-rich (O’Byrne et al. 1997) diets. 
A walnut-rich diet has recently been shown to improve endothelium-dependent vasodilation in hypercholesterolaemic subjects, suggesting lipid-independent beneficial effects (Ros et al. 2004). These results highlight the importance of fat type, as the fats found in nuts are predominantly mono- and polyunsaturated; however, nuts also contain other CHD-protecting factors such as vegetable protein, $\mathrm{Mg}$, vitamin $\mathrm{E}$, fibre and $\mathrm{K}$.

\section{Fatty acid intervention studies and CHD}

The first intervention trial altering fat content of the diet was carried out by Morrison (1951). MI survivors ( $n$ 100) were randomised to an experimental (dietary cholesterol intake $50-70 \mathrm{mg} / \mathrm{d}$, fat intake $20-25 \mathrm{~g} / \mathrm{d}$ ) or control diet. It was found that the experimental group lost on average $9 \mathrm{~kg}$ in weight and cholesterol dropped markedly, while there was no change in the control group. After 3 years of follow-up seven of the fifty subjects in the experimental group had died, compared with fifteen of the fifty subjects in the control group. After 12 years of follow-up nineteen of the fifty subjects in the experimental group had died and all fifty in the control group.

Since that early study a number of dietary trials have examined the effect of alteration in dietary fat and the effect on CHD. They have utilised two different approaches, either replacing saturated fat with polyunsaturated fat but leaving total fat unchanged or lowering total fat. In all the high-PUFA trials serum cholesterol was reported to be reduced (Leren, 1966, 1970; Morris et al. 1968; Dayton \& Pearce, 1969; Turpeinen et al. 1979; Frantz et al. 1989). Three of the trials (Dayton \& Pearce, 1969; Turpeinen et al. 1979; Frantz et al. 1989) were primary prevention trials conducted amongst institutionalised patients, which allowed a high extent of control over their diets. In the Los Angeles Veteran Hospital Study (Dayton \& Pearce, 1969) CHD rate was found to be reduced by $31 \%$ in the intervention group after 8 years, while in the Finnish Mental Hospital Study (Turpeinen et al. 1979) the reduction in CHD risk was reported to be $43 \%$ over 6 years. In contrast, in the Minnesota Coronary Survey (Frantz et al. 1989) cardiovascular events were not found to be reduced by a high-PUFA diet, despite a decrease in serum cholesterol, but the duration of the study was short. The two secondary prevention trials carried out in noninstitutionalised subjects (Leren, 1966, 1970; Morris et al. 1968) have reported contrasting results. In the Oslo DietHeart Study (Leren, 1966, 1970) a reduction in major coronary events was found at 5-year follow-up (Leren, 1966), with fatal MI rates still reduced at 11 years (Leren, 1970). In contrast, Morris et al. (1968) have shown no effect of soyabean oil on recurrent coronary events after 4 years, despite a $16 \%$ reduction in serum cholesterol at 6 months. The two interventions that tested total fat reduction (Ball et al. 1965; Burr et al. 1989) have reported no effect on either serum cholesterol or CHD events.

A meta-analysis by Truswell (1994) has shown that there is a direct relationship between the level of reduction in serum cholesterol by PUFA-rich diets and the effect on coronary events and all-cause mortality. The average reduction in serum cholesterol in fourteen trials was found to be $10 \%$. This reduction was found to be associated with a $13 \%$ reduction in coronary events and a $6 \%$ reduction in all-cause mortality. In the five trials with the largest reduction in serum cholesterol $(13 \%)$ a $30 \%$ reduction was observed for coronary events and an $11 \%$ reduction for all-cause mortality.

\section{n-3 PUFA intervention studies}

Marine-derived n-3 PUFA intervention studies. The first randomised controlled trial using $n$ - 3 PUFA was the Diet and Reinfarction Trial (Burr et al. 1989), which examined the effects of increased fatty fish intake on secondary prevention of CHD. A $29 \%$ reduction in allcause mortality was found over a 2 -year period in male MI survivors advised to increase intake of fatty fish by 200-400 g/week (providing an extra 500-800 mg $n-3$ PUFA/d). Analysis of a subset of patients who received fish oil capsules $(900 \mathrm{mg} \mathrm{EPA}+\mathrm{DHA} / \mathrm{d})$ has suggested the effect is associated with these fatty acids (Burr et al. 1994). However, after longer-term follow-up this protective effect was not found to persist (Ness et al. 2002), although this lack of effect may have been related to only small sustained increases in fish intake in the fish group. The recently-published second Diet and Reinfarction Trial (Burr et al. 2003) carried out in angina patients has not found a protective effect on mortality and has even shown a detrimental effect on (sudden) cardiac death.

Trials have also been carried out using fish oil capsules. Singh et al. (1997), in the Indian Experiment of Infarct Survival, randomised patients with suspected acute MI to fish oil capsules $(1.8 \mathrm{~g}$ EPA+DHA/d), mustard-seed oil $(20 \mathrm{~g} / \mathrm{d}$ providing $2.9 \mathrm{~g} \alpha$-linolenic acid/d) or placebo. At follow-up of 1 year it was shown that total cardiac events occurred in $25 \%$ and $28 \%$ of the fish oil and mustard-seed oil groups respectively compared with $35 \%$ of the placebo group, and the difference was significant $(P<0 \cdot 01)$.

To date, the largest randomised control trial carried out using $n-3$ PUFA is the Italian GISSI-Prevention Study (GISSI-Prevenzione Trial Group, 1999). In this secondary prevention study 11324 patients with pre-existing CHD were randomised to $300 \mathrm{mg}$ vitamin $\mathrm{E}$, fish oil $(850 \mathrm{mg}$ $\mathrm{EPA}+\mathrm{DHA}$ ), both vitamin $\mathrm{E}$ and fish oil or neither. After $3 \cdot 5$ years follow-up those subjects given $n$ - 3 PUFA alone were found to have a $15 \%$ reduction in the primary end point of death, non-fatal MI and non-fatal stroke $(P<0 \cdot 02)$, a $20 \%$ reduction in all-cause mortality $(P=0.01)$ and a $45 \%$ reduction in sudden death $(P<0 \cdot 001)$ compared with the control group. Vitamin $\mathrm{E}$ had no apparent effect on the primary end point, whether given alone or with the $n-3$ PUFA, although $P$ values approached significance. This trial was large and carried out in a relatively usual care setting (in that subjects were receiving conventional cardiac therapy). However, it was not placebo controlled (the control group received no intervention) and, therefore, is methodologically weaker than if a placebo control had been utilised. Dropout rates were also high $(>25 \%)$.

The last of the intervention studies with a clinical end point has compared maize oil with $3.5 \mathrm{~g}$ fish oil 
(concentrated in DHA+EPA)/d (Nilsen et al. 2001). No effect was seen on cardiac events in post-MI patients (n 300) after 1.5 years of intervention. The authors have speculated that this lack of effect may have been related to the high habitual fish intake in western Norway.

No intervention trials have been carried out so far that have examined the effect of $n$-3 PUFA supplementation on primary prevention of $\mathrm{CHD}$, although such trials are underway. However, several studies have examined the effect of supplementation on intermediate CHD end points.

The first study of the effect of $n$-3 PUFA on angiographic progression rates has shown no response to $6 \mathrm{~g} n-3$ PUFA or olive oil/d over 2 years (Sacks et al. 1995). However, a larger trial of patients presenting for coronary angiography ( $n$ 223), who were randomised to either placebo or $3 \mathrm{~g} / \mathrm{d}$ for 3 months followed by $1.5 \mathrm{~g} / \mathrm{d}$ for 21 months, has shown that $n$-3 PUFA supplementation is associated with less progression, more regression and a trend towards fewer clinical events (seven events $v$. two events; $P=0 \cdot 1$; von Schacky et al. 1999). Supplementation with $n$-3 PUFA $(3.4 \mathrm{~g} / \mathrm{d})$ has also been shown to lower vein graft occlusion rates from $33 \%$ (control) to $27 \%(P=0.03$; Eritsland et al. 1996).

Several trials have examined the effect of $n-3$ fish oils on restenosis (the closing or narrowing of an artery that has previously been opened by a cardiac procedure such as angioplasty) after coronary angioplasty. Although an early meta-analysis (of seven studies; Gapinski et al. 1993) has shown a beneficial effect of supplementation, the results of more recent trials (Cairns et al. 1996; Johansen et al. 1999) do not provide evidence of a beneficial effect. These later trials were large studies using 5-7g n-3 PUFA/d, and therefore further studies are not considered necessary.

Plant-derived n-3 PUFA intervention studies. The effect of $\alpha$-linolenic acid supplementation in CHD prevention has been examined in five trials (Natvig et al. 1968; Singh et al. 1997, 2002; de Lorgeril et al. 1999; Bemelmans et al. 2002). The Indian Experiment of Infarct Survival (Singh et al. 1997), discussed earlier, has reported a decrease in total cardiac events in the group assigned to mustard-seed oil. In the Lyon Diet Heart Study (de Lorgeril et al. 1999) a randomised controlled trial of an $\alpha$-linolenic acid-rich Mediterranean diet with free-living subjects, the subjects in the intervention group had a $50-70 \%$ reduction in cardiac end points. In the final report of this study de Lorgeril et al. (1999) have reported reductions in three composite outcomes (1, cardiac death and non-fatal MI; 2, outcome 1 plus unstable angina, stroke, heart failure and pulmonary or peripheral embolism; 3, outcome 2 plus minor events requiring hospital admission) with adjusted risk ratios ranging from 0.28 to 0.53 .

In terms of dietary change, subjects in the control group were reported to average ( $\%$ energy): 34 from fat; 12 from saturated fat; 11 from monounsaturated fat; 6 from polyunsaturated fat; $312 \mathrm{mg}$ cholesterol/d. In contrast, the values for subjects on the Mediterranean-style diet were reported to be ( $\%$ energy): 30 from fat; 8 from saturated fat; 13 from monounsaturated fat; 5 from PUFA; $203 \mathrm{mg}$ cholesterol/d. Those subjects on the Mediterranean diet were found to consume less linoleic acid (3.6\% energy $v$.
$5 \cdot 3 \%$ energy), but more oleic acid ( $12.9 \%$ energy $v .10 \cdot 8 \%$ energy), $\alpha$-linolenic acid ( $0 \cdot 84 \%$ energy v. $0 \cdot 29 \%$ energy) and dietary fibre. Plasma fatty acid analysis conducted after 52 weeks of follow-up confirmed the dietary fatty acid data (de Lorgeril et al. 1994). Although the plasma levels of $\alpha$-linolenic acid were shown to be associated with composite outcome 1 , it is impossible to ascribe the benefit unambiguously to $\alpha$-linolenic acid because of the changes in many other dietary variables.

The Indo-Mediterranean Diet Heart Study was a randomised single-blind trial of 1000 subjects with angina pectoris, MI or surrogate risk factors for coronary artery disease. The intervention group, who consumed a diet rich in $\alpha$-linolenic acid (rich in whole grains, fruits, vegetables, walnuts and almonds), had fewer total cardiac end points than the control group after 2 years (Singh et al. 2002). Also, in this case the intervention effect cannot be ascribed entirely to $\alpha$-linolenic acid.

These three positive studies of $\alpha$-linolenic acid are balanced by two negative studies (Natvig et al. 1968; Bemelmans et al. 2002). In the Norwegian Vegetable Oil Experiment (Natvig et al. 1968) 13000 men aged 50-59 years with no history of MI were randomly assigned to consume either $5.5 \mathrm{~g} \alpha$-linolenic acid (from $10 \mathrm{ml}$ linseed oil)/d or $10 \mathrm{ml}$ sunflower oil/d for 1 year. There were no differences between the groups in sudden death, death from CHD or all deaths. Similarly, the Mediterranean Alpha-Linolenic Enriched Groningen Dietary Intervention (Bemelmans et al. 2002) has examined 282 subjects with multiple CVD risk factors and randomised them to receive margarines rich in either $\alpha$-linolenic acid or linoleic acid, with a 2-year follow-up. No difference was found between groups in CHD risk, although there was a trend towards reduced CVD events in the $\alpha$-linolenic acid group $(P=0 \cdot 20)$.

These contradictory studies indicate that further welldesigned trials must be carried out in order to determine the role of $\alpha$-linolenic acid in CHD aetiology. Currently, the effects of plant $n-3$ PUFA as compared with those of marine $n-3$ PUFA are difficult to determine, as few, if any, studies have set out to test this comparison. For example, a meta-analysis of the available randomised control trials has examined all intervention trials whether they used marine or plant sources of $n-3$ PUFA and has found reductions in risk of non-fatal MI, fatal MI and sudden death, but does not distinguish between the two sources of $n-3$ PUFA (Bucher et al. 2002).

\section{Public health benefits of an alteration in fatty acid intake}

This overview of the relationships between fatty acids and CHD shows that a lot of evidence has been collected in controlled feeding studies, observational studies and clinical trials. However, the results of these studies are equivocal. Thus, a judgment has to be made about the strength of these relationships. An expert committee of the World Health Organization (2003) has judged recently that the relationships between SFA, trans-fatty acids and the $n-3$ PUFA EPA and DHA on the one hand and CHD on 
the other hand are convincing. For this reason The Netherlands Institute for Public Health and Environment has calculated the potential health gain that can be achieved if the current intake of these fatty acids in the Dutch diet is replaced by the recommended intake.

The recommendations of The Netherlands Health Council are: SFA $>10 \%$ energy intake; trans-fatty acids $>1 \%$ energy intake; fish consumption (an indicator of $n-3$ PUFA) once or twice weekly. This level of intake could reduce the incidence of CHD in The Netherlands by about $25000 /$ year and the number of CHD-related deaths by about 6000/year and increase life expectancy from age 40 years onwards by 0.5 years (The Netherlands Institute for Public Health and Environment, 2004). This projection shows the public health potential of interventions that modify the fatty acid composition of the diet.

\section{Conclusions}

Evidence from controlled feeding studies, epidemiological studies and clinical trials suggests that an alteration in the fatty acid composition of the diet has the potential to reduce CHD risk. SFA and trans-fatty acids increase CHD risk, while $n-6$ and $n-3$ PUFA act to decrease CHD risk. Optimisation of the fatty acid composition of the diet could have major public health benefits.

\section{References}

Abbey M, Noakes M, Belling GB \& Nestel PJ (1994) Partial replacement of saturated fatty acids with almonds or walnuts lowers total plasma cholesterol and low-density-lipoprotein cholesterol. American Journal of Clinical Nutrition 59, 995-999.

Abe Y, El-Masri B, Kimball KT, Pownall H, Reilly CF, Osmundsen K, Smith CW \& Ballantyne CM (1998) Soluble cell adhesion molecules in hypertriglyceridaemia and potential significance on monocyte adhesion. Arteriosclerosis, Thrombosis, and Vascular Biology 18, 723-731.

Abeywardena MY, McLennan PL \& Charnock JS (1991) Differential effects of dietary fish oil on myocardial prostaglandin I2 and thromboxane A2 production. American Journal of Physiology 260, H379-H385.

Agren JJ, Vaisanen S, Hanninen O, Muller AD \& Hornstra G (1997) Hemostatic factors and platelet aggregation after a fish-enriched diet or fish oil or docosahexaenoic acid supplementation. Prostaglandins, Leukotrienes, and Essential Fatty Acids 57, 419-421.

Ahlqwist M, Bengtsson C, Lapidus L, Gergdahl IA \& Schutz A (1999) Serum mercury concentration in relation to survival, symptoms, and diseases: results from the prospective population study of women in Gothenburg, Sweden. Acta Odontologica Scandinavica 57, 168-174.

Albert CM, Hennekens CH, O'Donnell CJ, Ajani UA, Carey VJ, Willett WC, Ruskin JN \& Manson JE (1998) Fish consumption and risk of sudden cardiac death. Journal of the American Medical Association 279, 23-28.

Ascherio A, Rimm EB, Giovannucci EL, Spiegelman D, Stampfer M \& Willett WC (1996) Dietary fat and risk of coronary heart disease in men: cohort follow up study in the United States. British Medical Journal 313, 84-90.

Ascherio A, Rimm EB, Stampfer MJ, Giovannucci EL \& Willett WC (1995) Dietary intake of marine n-3 fatty acids, fish intake, and the risk of coronary heart disease among men New England Journal of Medicine 332, 977-982.

Ball HP, Hanington E \& McAllen PM (1965) Low-fat diet in myocardial infarction: A controlled trial. Lancet ii, 501-504.

Bemelmans WJ, Broer J, Feskens EJ, Smit AJ, Muskiet FA, Lefrandt JD, Bom VJ, May JF \& Meyboom-de Jong B (2002) Effect of an increased intake of alpha-linolenic acid and group nutritional education on cardiovascular risk factors: the Mediterranean Alpha-linolenic Enriched Groningen Dietary Intervention (MARGARIN) study. American Journal of Clinical Nutrition 75, 221-227.

Brouwer IA, Katan MB \& Zock PL (2004) Dietary alphalinolenic acid is associated with reduced risk of fatal coronary heart disease, but increased prostate cancer risk: a metaanalysis. Journal of Nutrition 134, 919-922.

Bucher HC, Hengstler P, Schindler C \& Meier G (2002) N-3 polyunsaturated fatty acids in coronary heart disease: a metaanalysis of randomised controlled trials. American Journal of Medicine 112, 298-304.

Burr ML, Ashfield-Watt PA, Dunstan FD, Fehily AM, Breay P, Ashton T, Zotos PC, Haboubi NA \& Elwood PC (2003) Lack of benefit of dietary advice to men with angina: Results of a controlled trial. European Journal of Clinical Nutrition 57, 193-200.

Burr ML, Fehily AM, Gilbert JF, Rogers S, Holliday RM, Sweetnam PM, Elwood PC \& Deadman NM (1989) Effects of changes in fat, fish, and fibre intakes on death and myocardial reinfarction: diet and reinfarction trial (DART). Lancet ii, 757-761.

Burr ML, Sweetnam PM \& Fehily AM (1994) Diet and reinfarction. European Heart Journal 15, 1152-1153.

Cairns JA, Gill J, Morton B, Roberts R, Gent M, Hirsh J, Holder D, Finnie K, Marquis JF, Naqvi S \& Cohen E (1996) Fish oils and low-molecular weight heparin for the reduction of restenosis after percutaneous transluminal coronary angioplasty. The EMPAR Study. Circulation 94, 1553-1560.

Charnock JS (1994) Lipids and cardiac arrhythmia. Progress in Lipid Research 33, 355-385.

Chin JP \& Dart AM (1995) How do fish oils affect vascular function? Clinical and Experimental Pharmacology and Physiology 22, 71-81.

Daviglus ML, Stamler J, Orencia AJ, Dyer AR, Liu K, Greenland P, Walsh MK, Morris D \& Shekelle RB (1997) Fish consumption and the 30-year risk of fatal myocardial infarction. New England Journal of Medicine 336, 1046-1053.

Dayton S \& Pearce ML (1969) Prevention of coronary heart disease and other complications of arteriosclerosis by modified diet. American Journal of Medicine 46, 751-762.

De Backer G, Ambrosioni E, Borch-Johnson K, Brotons C, Cifkova R, Dallongeville J et al. (2003) European guidelines on cardiovascular disease prevention in clinical practice: Third Joint Task Force of European and other Societies on Cardiovascular Disease Prevention in Clinical Practice (constituted by representatives of eight societies and by invited experts). European Journal of Cardiovascular Prevention and Rehabilitation 10, S1-S78.

de Caterina R, Liao JK \& Libby P (2000) Fatty acid modulation of endothelial activation. American Journal of Clinical Nutrition 71, 213S-223S.

de Caterina R \& Libby P (1996) Control of endothelial leukocyte adhesion molecules by fatty acids. Lipids 31, S57-S63.

de Lorgeril M, Renaud S, Mamelle N, Salen P, Martin JL, Monjaud I, Guidollet J, Touboul P \& Delaye J (1994) Mediterranean alpha-linolenic acid-rich diet in secondary prevention of coronary heart disease. Lancet 343, 1454-1459.

de Lorgeril M, Salen P, Martin JL, Monjaud I, Delaye J \& Mamelle N (1999) Mediterranean diet, traditional risk factors, 
and the rate of cardiovascular complications after myocardial infarction. Final report of the Lyon Diet Heart Study. Circulation 99, 779-785.

de Roos NM, Bots ML, Siebelink E, Schouten E \& Katan MB (2001) Flow-mediated vasodilation is not impaired when HDL-cholesterol is lowered by substituting carbohydrates for monounsaturated fat. British Journal of Nutrition 86, 181-188.

Djousse L, Arnett DK, Carr JJ, Eckfeldt JH, Hopkins PN, Province MA \& Ellison RC (2005) Dietary linolenic acid is inversely associated with calcified atherosclerotic plaque in the coronary arteries. The National Heart, Lung and Blood Institute Family Heart Study. Circulation 111, 2921-2926.

Djousse L, Folsom AR, Province MA, Hunt SC \& Ellison RC (2003) Dietary linolenic acid and carotid atherosclerosis: the National Heart, Lung and Blood Institute Family Heart Study. American Journal of Clinical Nutrition 77, 819-825.

Dolecek TA (1992) Epidemiological evidence of relationships between dietary polyunsaturated fatty acids and mortality in the multiple risk factor intervention trial. Proceedings of the Society for Experimental Biology and Medicine 200, 177-182.

Dolecek TA \& Granditis G (1991) Dietary polyunsaturated fatty acids and mortality in the Multiple Risk Factor Intervention Trial (MRFIT). World Review of Nutrition and Dietetics 66, 205-216.

Dyerberg J \& Bang HO (1979) Haemostatic function and platelet polyunsaturated fatty acids in Eskimos. Lancet ii, 433-435.

Endres S \& von Schacky C (1996) n-3 Polyunsaturated fatty acids and human cytokine synthesis. Current Opinion in Lipidology 7, 48-52.

Eritsland J, Arnesen H, Gronseth K, Fjeld NB \& Abdelnoor M (1996) Effect of dietary supplementation with n-3 fatty acids on coronary artery bypass graft patency. American Journal of Cardiology 77, 31-36.

Erkkila AT, Lehto S, Pyorala K \& Uusitupa MI (2003) n-3 Fatty acids and 5-y risks of death and cardiovascular disease events in patients with coronary artery disease. American Journal of Clinical Nutrition 78, 65-71.

Esrey KL, Joseph L \& Grover SA (1996) Relationship between dietary intake and coronary heart disease mortality: lipid research clinics prevalence follow-up study. Journal of Clinical Epidemiology 49, 211-216.

Frantz ID Jr, Dawson EA, Ashman PL, Gatewood LC, Bartsch GE, Kuba K \& Brewer ER (1989) Test of effect of lipid lowering by diet on cardiovascular risk. The Minnesota Coronary Survey. Arteriosclerosis 9, 129-135.

Gapinski JP, VanRuiswyk JV, Heudebert GR \& Schectman GS (1993) Preventing restenosis with fish oils following coronary angioplasty: a meta-analysis. Archives of Internal Medicine 153, 1595-1601.

Garcia-Palmieri MR, Sorlie P, Tillotson J, Costas R Jr, Cordero E \& Rodriguez M (1980) Relationship of dietary intake to subsequent coronary heart disease incidence: The Puerto Rico Heart Health Program. American Journal of Clinical Nutrition 33, 1818-1827.

GISSI-Prevenzione Trial Group (1999) Dietary supplementation with n-3 polyunsaturated fatty acids and vitamin $\mathrm{E}$ after myocardial infarction: results of the GISSI-Prevenzione trial. Gruppo Italiano per lo Studio della Sopravvivenza nell'Infarcto miocardico. Lancet 354, 447-455.

Gordon T, Kagan A, Garcia-Palmieri M, Kannel WB, Zukel WJ, Tillotson J, Sorlie P \& Hjortland M (1981) Diet and its relation to coronary heart disease and death in three populations. Circulation 63, 500-515.

Grande F, Anderson JT \& Keys A (1970) Comparison of effects of palmitic and stearic acids in the diet on serum cholesterol in man. American Journal of Clinical Nutrition 23, 1184-1193.
Grundy SM, Bilheimer D, Blackburn H, Brown WV, Kwiterovich PO Jr, Mattson F, Schonfeld G \& Weidman WH (1982) Rationale of the diet-heart statement of the American Heart Association. Report of Nutrition Committee. Circulation 65, 839A-854A.

Grundy SM \& Denke MA (1990) Dietary influences on serum lipids and lipoproteins. Journal of Lipid Research 31, $1149-1172$.

Guallar E, Aro A, Jimenez FJ, Martin-Moreno JM, Salminen I, van't Veer P et al. (1999) Omega-3 fatty acids in adipose tissue and risk of myocardial infarction: the EURAMIC study. Arteriosclerosis, Thrombosis, and Vascular Biology 19, $1111-1118$.

Guallar E, Sanz-Gallardo MI, van't Veer P, Bode P, Aro A Gomez-Aracena J, Kark JD, Riemersma RA, Martin-Moreno JM \& Kok FJ; Heavy Metals and Myocardial Infarction Study Group (2002) Mercury, fish oils, and the risk of myocardial infarction. New England Journal of Medicine 347, 1747-1754.

Harris WS, Connor WE, Alam N \& Illingworth DR (1988) Reduction of postprandial triglyceridaemia in humans by dietary n-3 fatty acids. Journal of Lipid Research 29, $1451-1460$.

He K, Song Y, Daviglus ML, Liu K, van Horn L, Dyer AR \& Greenland P (2004) Accumulated evidence on fish consumption and coronary heart disease mortality: a meta-analysis of cohort studies. Circulation 109, 2705-2711.

Hegsted DM, Ausman LM, Johnson JA \& Dallal GE (1993) Dietary fat and serum lipids: an evaluation of the experimental data. American Journal of Clinical Nutrition 57, 875-883.

Hegsted DM, McGandy RB, Myers ML \& Stare FJ (1965) Quantitative effects of dietary fat on serum cholesterol in man. American Journal of Clinical Nutrition 17, 281-295.

Howe PR (1997) Dietary fats and hypertension: focus on fish oil. Annals of the New York Academy of Science 827, 339-352.

Hu FB, Manson JE \& Willett WC (2001) Types of dietary fat and risk of coronary heart disease: a critical review. Journal of the American College of Nutrition 20, 5-19.

Hu FB \& Stampfer MJ (1999) Nut consumption and risk of coronary heart disease: a review of epidemiologic evidence. Current Atherosclerosis Reports 1, 204-209.

Hu FB, Stampfer MJ, Manson JE, Rimm E, Colditz GA, Rosner BA, Hennekens CH \& Willett WC (1997) Dietary fat intake and the risk of coronary heart disease in women. New England Journal of Medicine 337, 1491-1499.

Hu FB \& Willett WC (2002) Optimal diets for prevention of coronary heart disease. Journal of the American Medical Association 288, 2569-2578.

Jacobs D, Blackburn H, Higgins M, Reed D, Iso H, McMillan G, Neaton J, Nelson J, Potter J \& Rifkind B (1992) Report of the Conference on Low Blood Cholesterol: Mortality Associations. Circulation 86, 1046-1060.

Jenkins DJ, Kendall CW, Marchie A, Faulkner DA, Wong JM, de Souza R et al. (2003) Effects of a dietary portfolio of cholesterol-lowering foods vs lovastatin on serum lipids and C-reactive protein. Journal of the American Medical Association 290, 502-510.

Johansen O, Brekke M, Seljeflot I, Abdelnoor M \& Arnesen H (1999) N-3 fatty acids do not prevent restenosis after coronary angioplasty: results from the CART study. Coronary Angioplasty Restenosis Trial. Journal of the American College of Cardiology 33, 1619-1626.

Johansen O, Seljeflot I, Hostmark AT \& Arnesen H (1999) The effect of supplementation with omega-3 fatty acids on soluble markers of endothelial function in patients with coronary heart disease. Arteriosclerosis, Thrombosis, and Vascular Biology 19, 1681-1686. 
Katan MB, Zock PL \& Mensink RP (1995) Trans fatty acids and their effects on lipoproteins in humans. Annual Review of Nutrition 15, 473-493.

Kato H, Tillotson J, Nichaman MZ, Rhoads GG \& Hamilton HB (1973) Epidemiologic studies of coronary heart disease and stroke in Japanese men living in Japan, Hawaii and California. American Journal of Epidemiology 97, 372-385.

Keys A (1980) Seven Countries: a Multivariate Analysis of Death and Coronary Heart Disease. Cambridge, MA: Harvard University Press.

Keys A \& Parlin RW (1966) Serum cholesterol response to changes in dietary lipids. American Journal of Clinical Nutrition 19, 175-181.

Krauss RM, Eckel RH, Howard B, Appel LJ, Daniels SR, Deckelbaum RJ et al. (2000) AHA Dietary Guidelines: revision 2000: A statement for healthcare professionals from the Nutrition Committee of the American Heart Association. Circulation 102, 2284-2299.

Kreisberg RA \& Oberman A (2003) Medical management of hyperlipidemia/dyslipidemia. Journal of Clinical Endocrinology and Metabolism 88, 2445-2461.

Kris-Etherton PM, Harris WS \& Appel LJ, for the Nutrition Committee (2002) Fish consumption, fish oil, omega-3 fatty acids, and cardiovascular disease. Circulation 106, 2747-2757.

Kromhout D (1998) Fish consumption and sudden cardiac death. Journal of the American Medical Association 279 . 65-66.

Kromhout D, Bloemberg BP, Feskens EJ, Hertog MG, Menotti A \& Blackburn H (1996) Alcohol, fish, fibre and antioxidant vitamin intake do not explain population differences in coronary heart disease mortality. International Journal of Epidemiology 25, 753-759.

Kromhout D, Bosschieter EB \& de Lezenne Coulander C (1985) The inverse relation between fish consumption and 20-year mortality from coronary heart disease. New England Journal of Medicine 312, 1205-1209.

Kromhout D \& de Lezenne Coulander C (1984) Diet, prevalence and 10-year mortality from coronary heart disease in 871 middle-aged men. The Zutphen Study. American Journal of Epidemiology 119, 733-741.

Kromhout D, Feskens EJ \& Bowles CH (1995a) The protective effect of a small amount of fish on coronary heart disease mortality in an elderly population. International Journal of Epidemiology 24, 340-345.

Kromhout D, Menotti A, Bloemberg B, Aravanis C, Blackburn H, Buzina R et al. (1995b) Dietary saturated and trans fatty acids and cholesterol and 25-year mortality from coronary heart disease: the Seven Countries Study. Preventive Medicine 24 308-315.

Kushi LH, Lew RA, Stare FJ, Ellison CR, el Lozy M, Bourke G, Daly L, Graham I, Hickey N \& Mulcahy R (1985) Diet and 20-year mortality from coronary heart disease. The IrelandBoston Diet-Heart Study. New England Journal of Medicine 312, 811-818.

Lee KW \& Lip GYH (2003) The role of omega-3 fatty acids in the secondary prevention of cardiovascular disease. Quarterly Journal of Medicine 96, 465-480.

Lemaitre RN, King IB, Mozaffarian D, Kuller LH, Tracy RP \& Siscovick DS (2003) N-3 polyunsaturated fatty acids, fatal ischemic disease, and nonfatal myocardial infarction in older adults: the Cardiovascular Health Study. American Journal of Clinical Nutrition 77, 319-325.

Leren P (1966) The effect of plasma cholesterol lowering diet in male survivors of myocardial infarction. A controlled clinical trial. Acta Medica Scandinavica 466, Suppl., 1-92.

Leren P (1970) The Oslo diet-heart study. Eleven-year report. Circulation 42, 935-942.
Lichtenstein AH, Ausman LM, Carrasco W, Jenner JL, Ordovas JM \& Schaefer EJ (1993) Hydrogenation impairs the hypolipidemic effect of corn oil in humans. Hydrogenation, trans fatty acids, and plasma lipids. Arteriosclerosis and Thrombosis 13, 154-161.

Lichtenstein AH, Ausman LM, Jalbert SM \& Schaefer EJ (1999) Effects of different forms of dietary hydrogenated fats on serum lipoprotein cholesterol levels. New England Journal of Medicine 340, 1933-1940.

Lovejoy JC (1999) Dietary fatty acids and insulin resistance. Current Atherosclerosis Reports 1, 215-220.

Lovejoy J \& DiGirolamo M (1992) Habitual dietary intake and insulin sensitivity in lean and obese adults. American Journal of Clinical Nutrition 55, 1174-1179.

Lu G, Windsor SL \& Harris WS (1999) Omega-3 fatty acids alter lipoprotein subfraction distributions and the in vitro conversion of very low density lipoproteins to low density lipoproteins. Journal of Nutritional Biochemistry 10, 151-158.

McGee DL, Reed DM, Yano K, Kagan A \& Tillotson J (1984) Ten-year incidence of coronary heart disease in the Honolulu Heart Program. Relationship to nutrient intake. American Journal of Epidemiology 119, 667-676.

McVeigh GE, Brennan GM, Cohn JN, Finkelstein SM, Hayes RJ \& Johnston GD (1994) Fish oil improves arterial compliance in non-insulin-dependent diabetes mellitus. Arteriosclerosis and Thrombosis 14, 1425-1429.

Mann JI (2002) Diet and risk of coronary heart disease and type 2 diabetes. Lancet 360, 783-789.

Marckmann P \& Gronbaek M (1999) Fish consumption and coronary heart disease mortality: a systematic review of prospective cohort studies. European Journal of Clinical Nutrition 53, 585-590.

Mensink RP (2005) Metabolic and health effects of isomeric fatty acids. Current Opinion in Lipidology 16, 27-30.

Mensink RP \& Katan MB (1992) Effect of dietary fatty acids on serum lipids and lipoproteins. A meta-analysis of 27 trials. Arteriosclerosis and Thrombosis 12, 911-919.

Mensink RP, Zock PL, Kester AD \& Katan MB (2003) Effects of dietary fatty acids and carbohydrates on the ratio of serum total to HDL cholesterol and on serum lipids and apolipoproteins: a meta-analysis of 60 controlled trials. American Journal of Clinical Nutrition 77, 1146-1155.

Mori TA, Beilin LJ, Burke V, Morris J \& Ritchie J (1997) Interactions between dietary fat, fish and fish oils and their effects on platelet function in men at risk of cardiovascular disease. Arteriosclerosis, Thrombosis, and Vascular Biology 17, 279-286.

Morris JN, Ball KP \& Antonis A (1968) Controlled trial of soyabean oil in myocardial infarction. Lancet ii, 693-699.

Morris MC, Sacks F \& Rosner B (1993) Does fish oil lower blood pressure? A meta-analysis of controlled trials. Circulation 88, 523-533.

Morrison LM (1951) Reduction of mortality rate in coronary atherosclerosis by a low cholesterol-low fat diet. American Heart Journal 42, 538-545.

Mutanen M \& Freese R (1996) Polyunsaturated fatty acids and platelet aggregation. Current Opinion in Lipidology 7, 14-19.

Nair SSD, Leitch JW, Falconer J \& Garg ML (1997) Prevention of cardiac arrhythmia by dietary (n-3) polyunsaturated fatty acids and their mechanism of action. Journal of Nutrition 127, 383-393.

Natvig H, Borchgrevink CF, Dedichen J, Owren PA, Schiotz EH \& Westlund K (1968) A controlled trial of the effect of linolenic acid on the incidence of coronary heart disease. Scandinavian Journal of Clinical and Laboratory Medicine 105, S1-S20. 
Ness AR, Hughes J, Elwood PC, Whitley E, Smith GD \& Burr ML (2002) The long-term effect of dietary advice in men with coronary disease: follow-up of the Diet and Reinfarction Trial (DART). European Journal of Clinical Nutrition 56, 512-518.

Nestel P, Noakes M, Belling B, McArthur R, Clifton P, Janus E \& Abbey M (1992) Plasma lipoprotein lipid and Lp[a] changes with substitution of elaidic acid for oleic acid in the diet. Journal of Lipid Research 33, 1029-1036.

Nicolosi RJ, Stucchi AF, Kowala MC, Hennessy LK, Hegsted DM \& Schaefer EJ (1990) Effect of dietary fat saturation and cholesterol on LDL composition and metabolism. In vivo studies of receptor and nonreceptor-mediated catabolism of LDL in cebus monkeys. Arteriosclerosis 10, 119-128.

Nilsen DW, Albrektsen G, Landmark K, Moen S, Aarsland T \& Woie L (2001) Effects of a high dose concentrate of n-3 fatty acids or corn oil introduced early after an acute myocardial infarction on serum triacylglycerol and HDL cholesterol. American Journal of Clinical Nutrition 74, 50-56.

O'Byrne DJ, Knauft DA \& Shireman RB (1997) Low fatmonounsaturated rich diets containing high-oleic peanuts improve serum lipoprotein profiles. Lipids 32, 687-695.

Oomen CM, Feskens EJ, Rasanen L, Fidanza F, Nissinen AM, Menotti A, Kok FJ \& Kromhout D (2000) Fish consumption and coronary heart disease mortality in Finland, Italy and the Netherlands. American Journal of Epidemiology 151, 999-1006.

Oomen CM, Ocke MC, Feskens EJM, van Erp-Baart M-AJ, Kok FJ \& Kromhout D (2001) Association between trans fatty acid intake and 10-year risk of coronary heart disease in the Zutphen Elderly Study: a prospective population-based study. Lancet 357, 746-751.

Pietinen P, Ascherio A, Korhonen P, Hartman AM, Willett WC, Albanes D \& Virtamo J (1997) Intake of fatty acids and risk of coronary heart disease in a cohort of Finnish men: the AlphaTocopherol, Beta-Carotene Cancer Prevention Study. American Journal of Epidemiology 145, 876-887.

Posner BM, Cobb JL, Belanger AJ, Cupples LA, D'Agostino RB \& Stokes J 3rd (1991) Dietary lipid predictors of coronary heart disease in men. The Framingham Study. Archives of Internal Medicine 151, 1181-1187.

Rallidis LS, Paschos G, Papaioannou ML, Liakos GK, Panagiotakos DB, Anastasiadis G \& Zampelas A (2004) The effect of diet enriched with alpha-linolenic acid on soluble cellular adhesion molecules in dyslipidaemic patients. Atherosclerosis 174, 127-132.

Ros E, Nunez I, Perez-Heras A, Serra M, Gilabert R, Casals E \& Deulofeu R (2004) A walnut diet improves endothelial function in hypercholesterolaemic subjects - a randomized crossover trial. Circulation 109, 1609-1614.

Sabate J (1993) Does nut consumption protect against ischaemic heart disease? European Journal of Clinical Nutrition 47, S71-S75.

Sacks F (1994) Dietary fats and coronary heart disease. Overview. Journal of Cardiovascular Risk 1, 3-8.

Sacks FM, Stone PH, Gibson CM, Silverman DI, Rosner B \& Pasternak RC (1995) Controlled trial of fish oil for regression of human coronary atherosclerosis. HARP Research Group. Journal of the American College of Cardiology 25, 1492-1498.

Salonen JT, Seppanen K, Lakka TA, Salonen R \& Kaplan GA (2000) Mercury accumulation and accelerated progression of carotid atherosclerosis: a population-based prospective 4-year follow-up study in men in eastern Finland. Atherosclerosis $\mathbf{1 4 8 ,}$ 265-273.

Seljeflot I, Arnesen H, Brude IR, Nenseter MS, Drevon CA \& Hjermann I (1998) Effects of omega-3 fatty acids and/or antioxidants on endothelial cell markers. European Journal of Clinical Investigation 28, 629-635.

Sheard NF (1998) Fish consumption and risk of sudden cardiac death. Nutrition Reviews 56, 177-179.

Shekelle RB, Missell L, Paul O, Shryock AM \& Stamler J (1985) Fish consumption and mortality from coronary heart disease. New England Journal of Medicine 313, 820.

Shekelle RB, Shryock AM, Paul O, Lepper M, Stamler J, Liu S \& Raynor WJ Jr (1981) Diet, serum cholesterol, and death from coronary heart disease. The Western Electric Study. New England Journal of Medicine 304, 65-70.

Simopoulos AP (2002) Omega-3 fatty acids in inflammation and autoimmune disease. Journal of the American College of Nutrition 21, 495-505.

Singh RB, Dubnov G, Niaz MA, Ghosh S, Singh R, Rastogi SS, Manor O, Pella D \& Berry EM (2002) Effect of an IndoMediterranean diet on progression of coronary artery disease in high risk patients (Indo-Mediterranean Diet Heart Study): a randomised single-blind trial. Lancet 360, 1455-1461.

Singh RB, Niaz MA, Sharma JP, Kumar R, Rastogi V \& Moshiri M (1997) Randomised, double-blind, placebo-controlled trial of fish oil and mustard oil in patients with suspected acute myocardial infarction: the Indian experiment of infarct survival. Cardiovascular Drugs and Therapy 11, 485-491.

Spady DK, Bilheimer DW \& Dietschy JM (1983) Rates of receptor-dependent and -independent low density lipoprotein uptake in the hamster. Proceedings of the National Academy of Sciences USA 80, 3499-3503.

Spiller GA, Jenkins DJ, Cragen LN, Gates JE, Bosello O, Berra K, Rudd C, Stevenson M \& Superko R (1992) Effect of a diet high in monounsaturated fat from almonds on plasma cholesterol and lipoproteins. Journal of the American College of Nutrition 11, 126-130.

Sundram K, Ismail A, Hayes KC, Jeyamalar R \& Pathmanathan R (1997) Trans (elaidic) fatty acids adversely affect the lipoprotein profile relative to specific saturated fatty acids in humans. Journal of Nutrition 127, 514S-520S.

The Netherlands Institute for Public Health and Environment (2004) Ons eten gemeten. Gezonde voeding en veilig voedsel in Nederland (Our Food Measured. Healthy Eating and Safe Food in The Netherlands), pp. 55-97. Houten, The Netherlands: Bohn Stafleu Van Loghum.

Thies F, Garry JMC, Yaqoob P, Rerkasem K, Williams J, Shearman CP, Gallagher PJ, Calder PC \& Grimble RF (2003) Association of n-3 polyunsaturated fatty acids with stability of atherosclerotic plaques: a randomized controlled trial. Lancet 361, 477-485.

Tholstrup T, Hellgren LI, Petersen M, Basu S, Straarup EM, Schnohr P \& Sandstrom B (2004) A solid dietary fat containing fish oil redistributes lipoprotein subclasses without increasing oxidative stress in men. Journal of Nutrition 134, 1051-1057.

Trebble TM, Wootton SA, Miles EA, Mullee M, Arden NK, Ballinger AB, Stroud MA, Burdge GC \& Calder PC (2003) Prostaglandin $\mathrm{E}_{2}$ production and $\mathrm{T}$ cell function after fish-oil supplementation: response to antioxidant cosupplementation. American Journal of Clinical Nutrition 78, 376-382.

Truswell AS (1994) Review of dietary intervention studies: effect on coronary events and on total mortality. Australia and New Zealand Journal of Medicine 24, 98-106.

Turpeinen AM, Wubert J, Aro A, Lorenz R \& Mutanen M (1998) Similar effects of diets rich in stearic acid or trans-fatty acids on platelet function and endothelial prostacyclin production in humans. Arteriosclerosis, Thrombosis, and Vascular Biology 18, 316-322.

Turpeinen O, Karvonen MJ, Pekkarinen M, Miettinen M, Elosuo R \& Paavilainen E (1979) Dietary prevention of 
coronary heart disease: the Finnish Mental Hospital Study. International Journal of Epidemiology 8, 99-118.

Verschuren WM, Jacobs DR, Bloemberg BP, Kromhout D, Menotti A, Aravanis C, Blackburn H, Buzina R, Dontas AS \& Fidenza F (1995) Serum total cholesterol and long-term coronary heart disease mortality in different cultures. Twentyfive year follow-up of the Seven Countries Study. Journal of the American Medical Association 274, 131-136.

von Schacky C, Angerer P, Kothny W, Theisen K \& Mudra H (1999) The effect of dietary omega-3 fatty acids on coronary atherosclerosis: a randomised, double-blind, placebo-controlled trial. Annals of Internal Medicine 130, 554-562.

Whelton SP, He J, Whelton PK \& Muntner P (2004) Meta-analysis of observational studies on fish intake and coronary heart disease. American Journal of Cardiology 93, 1119-1123.
World Health Organization (2003) Diet, Nutrition and Prevention of Chronic Diseases. Report of a WHO/FAO Expert Consultation. Technical Report Series no. 916. Geneva: WHO.

Yu S, Derr J, Etherton TD \& Kris-Etherton PM (1995) Plasma cholesterol-predictive equations demonstrate that stearic acid is neutral and monounsaturated fatty acids are hypocholesterolemic. American Journal of Clinical Nutrition 61, 1129-1139.

Zhang J, Sasaki S, Amano K \& Kestelot H (1999) Fish consumption and mortality from all causes, ischemic heart disease, and stroke: an ecological study. Preventive Medicine 28, 520-529.

Zhao G, Etherton TD, Martin KR, West SG, Gillies PJ \& Kris-Etherton PM (2004) Dietary alpha-linolenic acid reduces inflammatory and lipid cardiovascular risk factors in hypercholesterolemic men and women. Journal of Nutrition 134, 2991-2997. 